\title{
DisCUSSION ON LARGE-SCALE ONLINE Education Practices AMId THE NOVEL CORONAVIRUS OUTBREAK
}

\author{
Xiaojie Geng \\ China University of Geosciences, Beijing, China
}

\begin{abstract}
The delay of the school term in China, caused by the Corona Virus Disease 2019 (COVID-19) pandemic, reinforced the importance of remote teaching. The latter enabled teaching operations to continue nationwide and provided colleges and universities with opportunities to carry out education and teaching reforms that are also aligned with the rapid development of technology. Upon considering remote teaching operations in China University of Geosciences, Beijing, this paper puts forward recommendations for teaching and education management practices. We propose that colleges and universities break free from the restraints of traditional teaching methods, establish a security system of online courses, offer high quality online contents, and accelerate the construction and sharing of effective courses.
\end{abstract}

\section{KEYWORDS}

Online teaching, Educational Management, information construction

\section{INTRODUCTION}

Teaching in the 2020 spring semester was a challenge for universities across China. In view of the impacts of COVID-19 on university education, the Chinese Minister of Education issued the report entitled "Guidance on Organizing and Managing Online teaching in Ordinary Colleges and Universities" during the period of epidemic prevention and control. The Ministry called for government and educational institutions to jointly implement and guarantee remote teaching in colleges and universities.

During this time, university teachers and managers were able to quickly research and implement innovative higher education. They also adapted to ensure the quality of education and to improve their ability to manage courses. We believe that the extensive development of online teaching will have an important impact on the educational reform in colleges and universities, especially pertaining to the ways that administrators manage online teaching.

\section{The basic Circumstance of Online Teaching}

In response to the statement of the Ministry of Education that "classes should not stop teaching and classes should not be suspended", China university of Geosciences Beijing published a series of documents to guide the implementation of online education in the early stage of the spring semester, including the "Notice on the Implementation of Online Teaching during the Extension Period", "The Plan on the Postponed Undergraduate Education and Teaching Work", "The Operation Guide for Online Teaching Teachers of China University of Geosciences" and more. 
The number of courses offered online was growing with the introduction of university policies. From February 1 to February 14, two weeks before the start of the 2020 spring semester, there were 756 teachers, 750 courses being taught online. The total number of students participating in remote learning is 97,710 , and the class attendance rate of students was more than $97.6 \%$ every week. All online courses were running smoothly. Since the launch of remote teaching, the continuous exploration and adjustment of remote teaching methods and management models are the most important reason for the normal teaching of the university.

\section{The Change of Teachers' Functions And Teaching Concepts}

The concept of "student-oriented" has been strengthened by large-scale online education. Most of the teachers who worked in universities should make great efforts to meet the needs of personalized learning.

\subsection{The Transformation of Teachers' Functions}

Teachers become the designer and the leader of the learning process. They also become instructors and servers in the process instead of knowledge imparters. These changes run through every aspect of online teaching [1].

For example, the China University of Geosciences, Beijing, runs 1207 undergraduate online courses every week, where $92.7 \%$ of the teachers choose to conduct online teaching based on "fast course" on the Chaoxing platform. Teachers need to prepare curriculum resources in advance, including videos, pictures, sounds, texts, etc., and upload them to the learning platform. Questions arise such as, how to set the length of each video? When to insert the appropriate question? How to guide students to learn step-by-step? The arrangement of curriculum resources online requires educators to think about the logic of their curriculum design.

At the same time, teachers need to make plans to deal with emergencies. In case of network instability and major platform congestion, it is necessary to rapidly expand teaching tools to ensure the smooth completion of the course.

Practical courses are much more difficult than theoretical courses. Teachers could offer live demonstrations of the specific operation during class time, which would help develop student skills.

For language courses, more dialogue is required, so teachers could upload the course outline before class, broadcast the exchange during class, and expand on the supplementary materials after class.

During this online education practice, a large number of teaching moods were produced by teachers, such as "fast class+ synchronous class", QQ live studio + Meeting rooms" "We Chat online discussing groups", etc. They made online learning more convenient for students.

\subsection{The Transformation of Teaching Concept}

The changes in teachers' functions and roles online are motivated by the transformation of teaching concepts. The quality of online courses depends on the understanding of their lecturers to a great extent [2]. They should have the motivation to change from traditional teaching methods. The improvement of teachers' knowledge of theory and ability to access data and hightech applications should be reflected in all aspects of teaching. 
The main design of online teaching also features "inductive" and "heuristic" teaching methods, to help students improve their understanding and mastery of curriculum knowledge through selflearning. It also arouses the enthusiasm of students to participate in the curriculum and tap into their own learning potential and learning thinking. All online course designs should work towards the same objective to promote the students' understanding and applications of the curriculum knowledge. To form an excellent large-scale remote course system, we suggest that colleges and universities should burst from the restraints of traditional teaching concepts.

\subsection{To Make Good Connection Between Online And In-Person Teaching}

Online teaching is an emergency plan to solve the current problems caused by the epidemic, but it should not be the relied upon for teaching operations in the long-term. The approaches and objectives of online and in-person teaching are quite different. The goals of online courses are to consolidate the foundation and cultivate students' autonomous learning ability. It helps students comprehend the course system. After taking online courses, students' views are broadened by their mass of the network content.

However, in-person teaching is essential to university education because the communication and emotional resonance between teachers and students are barely sufficient online. After the epidemic is under control nationwide, the primary task for university will likely be to resume operations. Most of the online courses will revert to classroom teaching. Teachers only connected online and in-person teaching during the epidemic. The depth and breadth of online content should be deliberately designed in the future.

\section{Adjustment and Practice of Teaching Management}

The management mode online is different from traditional classroom teaching in every aspect, from daily operation management to teaching quality evaluation. In response to the new situation, there will also be many new adjustments in university teaching management.

\subsection{To Improve the Level of Information Management and Ensure the Quality of teaching}

In order to quickly adapt to the management of remote courses, educational administrators in colleges and universities should have high information literacy, to manage the course system smoothly and solve the problems in the management process [3]. They should be able to effectively supervise students' course selection, online learning, student assessment and credit recognition, and accurately judge the teaching design, resource arrangement and learning effect of online courses.

The university managers should mine big data from their learning management platforms and strengthen the monitoring and analysis of the latter. Students' learning activities could be shared in a common database, and the whole process of teaching activities will be reviewed and checked in detail by means of index and search. Statistical analyses of the teaching process and teaching effects put forward targeted guidance and solutions to improve management efficiency. Meanwhile, administrators can formulate guidelines for remote learning and measures for the management of courses taught remotely, to ensure the orderly development of high quality programming. 


\subsection{To Organize Systematic Training and Improve the Information Level of University Teachers}

Teachers with professionalism, knowledge management skills and continuous learning ability are needed to improve the quality of online courses. Faculty-building depends on scientific and systematic training mechanisms [4]. With the last minute construction of online courses and limited training on the matter, a number of teachers in the China University of Geosciences Beijng struggled information technology. The teaching management department should take the needs of teachers as the starting point, and carry out targeted training on teaching philosophies, professional knowledge, and information technology. This could help teachers gain the knowledge and skills of online teaching, to deal with the particularity of online teaching and the complexity of a network environment.

From the perspective of school professionals, we should carry out a set of scientific teaching strategies. In order to adapt to the new environment and requirements of online education, universities have an obligation to improve teachers' information literacy.

\subsection{To Accelerate the Standardization of Online Courses}

Standardization is necessary to the long-term development of remote programming. The largescale development of online teaching will certainly aid the education and teaching systems in colleges and universities to develop into decentralized virtual online classroom teaching forms.

It is difficult for some educators and administrators to evaluation online teaching, as evaluation methods and standards online differ from those used in the classroom. Imposing strict teaching evaluation standards is important to improving the quality of education in universities and colleges, and relevant to teaching management. Program evaluators should also pay attention to the quality of the curriculum [5].

The teaching management departments should formulate the standards for teaching, the curriculum, course operations, credit certification, workload calculation, teaching evaluation, network technology, and curriculum certification. They should conduct regular evaluations of online courses. They should also establish evaluation standards for the effects of remote courses on student learning, integrity, and enthusiasm when engaging with the platform for their course. Credit certification and student status management also need to be gradually innovated to adapt to the development of large-scale online teaching. In addition to perfecting the university evaluation mechanisms for courses, there should also be an effective feedback mechanism to form a system of closed loop control and optimize online course resources [3].

\section{Comprehensive layout to Promote the Construction of COLLEGE TEACHING INFORMATION}

In these unusual times, the development of a large-scale remote teaching approach is a challenge for universities. We believe the current context will encourage postsecondary institutions to improve their information technologies levels and attach importance to remote teaching, so that they may strategically engage in the development of a long-term plan for the latter.

\subsection{To Build Online Course System at the School Level}

At present, 22 online course platforms organized by the Ministry of Education provide access to more than 24,000 online courses free of charge, covering 12 disciplines for undergraduates and 
18 major fields for junior colleges and vocational colleges. As a professional university, Wuhan University should combine the characteristics of geology adopt the advanced teaching ideas and teaching methods of the first-class universities at home and abroad, and tap into effective curriculum resources from various disciplines and successful faculty, to integrate into the institution's. Distinctive online course system. Wuhan University should promote the development and sharing of high-quality teaching resources, to help enhance the popularity of the school, and take this opportunity to drive the construction of other excellent courses, to promote curriculum reform and to improve the quality of teaching.

\subsection{To Explore the Reform of Teaching in the Information Age}

In the context of education informatization, remote teaching has become an important way to globalize education. After the end of the epidemic, most courses will resume in-person teaching. With the current experiences leading universities to create a framework for remote learning, it is possible that educators will mix their teaching approaches to accommodate learning in-person and through online platforms. Colleges and universities should actively promote this type of reform, and encourage college teachers to change how they integrate information technologies and approaches into their teaching, such as introducing the 'flipped classroom' approach and encouraging students' autonomous learning through online activities.

\subsection{Accelerating the Introduction of an Online Course Management Policy System}

The development of remote courses has overturned the traditional teaching model and brought great changes to university education. A scientific management policy is the guarantee of the normal operation and management of the educational administration information system. It is necessary to establish and improve various rules and regulations pertinent to learning online and use a system to guide and standardize teaching with information technologies. For example, a series of management systems have been created for building and managing remote courses, for credit recognition in the remote learning context, and for evaluating remote teaching, which in turn help institutions carry out remote teaching reforms.

In addition, teachers need time and training to learn how to work with technology to construct, plan, and operate their courses, and how to monitor their students' activities and performances on learning platforms [6]. At the institutional level, achieving the successful construction of remote courses should be taken as an important basis for the assessment of professional titles and the appointment of posts.

\section{Conclusions}

Large-scale online teaching poses systematic and comprehensive challenges to the traditional teaching model and to educational administration management in colleges and universities. We argue that it is necessary to meet these challenges from a higher level such as in universities.

During the Covid-19 pandemic, the trial and operations of online education nationwide accelerated and will continue to affect the process of digital informatization construction in universities. Universities should seize the opportunity to implement reforms relate to teaching and educational technology and to accelerate the development of higher education information. In sum, the recommendations in this paper may provide managers in universities with clearer direction for improvements. 


\section{ACKNOWLEDGEMENTS}

This work was supported by the National Scientific Funding Project (72041020) and the Undergraduate education quality improvement plan 2020 in China University of Geosciences, Beijing. Authors are thankful to anonymous referees for providing useful and fair review.

\section{REFERENCES}

[1] Mao Hui, He Yunfeng, Wang Ning. Research on the strategy of college teacher development in the wave of MOOCs, Theory and Practice of Education, Vol.37, pp18-20.

[2] Yan Jun. Analysis of teaching and learning behavior based on MOOC, Heilongiiang Science, Vol.11, pp30-31.

[3] Liu Jun, Sheng Nannan. Research on the Problems Existing in the Teaching Management of MOOC Teaching and Countermeasures in Independent Colleges, Journal of Jilin Radio and TV University, Vol.201, pp58-59.

[4] Ding Jinhong, Qian Xiaolong. Paths for MOOC Construction in teaching-reasearch universities, Higher Education Development and Evaluation, Vol.35, pp87-98.

[5] Xiang Wenjiang, Tang Jie, Zhou Ping. A study of teaching management reform of local colleges in the context of MOOC, China Modern Educational Equipment, Vol.221, pp22-25.

[6] Zhong Bin, Cai Zhongbing, Guo Binai. Research on MOOC-Based teaching management, Journal of Guangzhou Open University, Vol.17, pp26-30.

\section{AUTHOR}

Xiaojie Geng, earned her Ph.D.in Mineral resource prospecting and exploration in 2015 from China university of Geosciences, Beijing. Her research is focus on higher education management since she began to work.

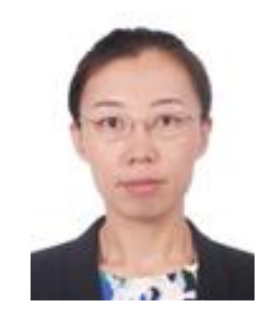

